\title{
DREAM Complex
}

National Cancer Institute

\section{Source}

National Cancer Institute. DREAM Complex. NCI Thesaurus. Code C160744.

A protein complex that is involved in the repression of cycle-dependent gene expression during the G0 phase. 